\title{
Effect of pulmonary arteriovenous malformations on the mechanical properties of the lungs
}

\author{
Cécile Rotenberg ${ }^{\dagger}$, Marcel Bonay ${ }^{\dagger}$, Mostafa El Hajjam, Sandra Blivet, Alain Beauchet, Pascal Lacombe
} and Thierry Chinet ${ }^{*}$ (1)

\begin{abstract}
Background: Pulmonary arteriovenous malformations (PAVMs) are present in approximately 15-50\% individuals with hereditary hemorrhagic telangiectasia $(\mathrm{HHT})$. They may be isolated but more often are multiple. The goal of this study was to evaluate the influence of PAVMs on lung mechanical properties.

Methods: We reviewed the files of all adult patients (age $\geq 18$ years) referred to our Center for evaluation of HHT between 2005 and 2013. The diagnosis of HHT was based on the Curacao criteria and/or the presence of a pathogenic mutation. Exclusion criteria included: chronic cardiac or lung disease (i.e. asthma or COPD), suspicion of pulmonary hypertension on echocardiography, current or past smoking (>10 pack-years), history of thoracic surgery, previous treatment of PAVMs by embolotherapy, lung infection or thromboembolic disease in the past 3 months, pregnancy and obesity $\left(B M I>30 \mathrm{~kg} / \mathrm{m}^{2}\right)$. Chest high resolution CT-scan and pulmonary function tests were performed the same day in all patients as part of our routine work-up.

Results: One hundred and fifty five patients with HHT were included (age: $44.4 \pm 16.7$ yrs - mean \pm SD -; males: 39\%). Eighty eight patients had no PAVM, 45 had 1-3 PAVMS and 22 had at least 4 PAVMs. Thirty eight patients had unilateral PAVMs and 29 bilateral PAVMs. We found no statistical relationship between the number, the size and the laterality of PAVMs and results of lung flows and volumes.
\end{abstract}

Conclusion: We found no evidence that PAVMs have a significant influence on lung mechanical properties as measured using routine pulmonary function tests in adult patients with HHT, even in case of numerous, macroscopic or bilateral malformations.

Keywords: Pulmonary arteriovenous malformation, Lung function, Hereditary hemorrhagic telangiectasia

\section{Background}

Pulmonary arteriovenous malformations (PAVMs) are abnormal structures that connect the pulmonary arterial circulation to the pulmonary venous circulation without a capillary network, resulting in right-to-left shunt (RLS) $[1,2]$. More than $80 \%$ of PAVMs are associated with an autosomal dominant genetic disease, hereditary hemorrhagic telangiectasia (HHT). HHT affects approximately $1-5 / 8000$ people. HHT is caused by mutations in the endoglin $(E N G)$ gene, the activin A receptor type

\footnotetext{
* Correspondence: thierry.chinet@aphp.fr

${ }^{\dagger}$ Equal contributors

Consultation Pluridisciplinaire Maladie de Rendu Osler, Université de Versailles SQY, APHP, Hôpital Ambroise Paré, Boulogne-Billancourt, France
}

II-like 1 (ACVRL1/ALK1) gene, and rarely, the smad4 gene [3]. PAVMs are found in $15 \%$ to $50 \%$ of HHT patients; $40 \%$ to $75 \%$ patients have ENG mutations and $5 \%$ to $45 \%$ patients have ACVRL1/ALK1 mutations. These vascular malformations expose patients to severe complications due to paradoxical systemic emboli of thrombotic or septic origin, such as stroke and brain abscess [1-5]. PAVMs may be single or multiple, and unilateral or bilateral [1]. Although the natural history of PAVMs is not well known, evidence shows that a significant proportion may grow during follow-up $[1,2,6]$.

Patients with PAVMs often complain of dyspnea $[1,7,8]$. This is related, at least in part, to the presence of RLS. We hypothesized that the presence of PAVMs may also

\section{$\int$ Biomed Central}

(c) The Author(s). 2017 Open Access This article is distributed under the terms of the Creative Commons Attribution 4.0 International License (http://creativecommons.org/licenses/by/4.0/), which permits unrestricted use, distribution, and reproduction in any medium, provided you give appropriate credit to the original author(s) and the source, provide a link to the Creative Commons license, and indicate if changes were made. The Creative Commons Public Domain Dedication waiver (http://creativecommons.org/publicdomain/zero/1.0/) applies to the data made available in this article, unless otherwise stated. 
impair the respiratory mechanical properties in relation to the number and/or size of PAVMs and therefore contribute to dyspnea.

Previous studies have reported the results of pulmonary function tests (PFTs) in patients with HHT and PAVMs [7, 9-12]. Most patients had normal resting pulmonary function values, while others showed a restrictive or an obstructive pattern (9\% and 15\%, respectively, in the largest series). However, patients were not selected according to the presence or absence of chronic heart or pulmonary diseases or previous lung surgery or embolization. Therefore, whether the reported abnormalities were related to PAVMs or to other conditions is unclear. Furthermore, no study has attempted to correlate the number or size of PAVMs with lung function values. We therefore decided to evaluate the influence of PAVMs on lung mechanical properties as measured using routine PFTs.

\section{Methods}

\section{Study participants}

We retrospectively reviewed the files of all consecutive adult patients with HHT who were referred to our center for evaluation between 2005 and 2013. The diagnosis of HHT was based on Curacao's criteria and/or the presence of a pathogenic mutation [3]. Exclusion criteria included the following: age $<18$ years, chronic cardiac or lung disease (such as asthma or COPD), suspicion of pulmonary hypertension on echocardiography, lung infection or thromboembolic disease in the past 3 months, current or past smoking (>10 pack-years), history of thoracic surgery, history of embolotherapy of PAVMs, pregnancy, and obesity (body mass index $>30 \mathrm{~kg} / \mathrm{m}^{2}$ ). All patients underwent our routine evaluation protocol during the same day. This protocol usually included high resolution chest computed tomography, contrast echocardiography, PFTs, and genetic testing.

PFTs included measurements of total lung capacity (TLC), vital capacity (VC), forced expiratory volume in $1 \mathrm{~s}\left(\mathrm{FEV}_{1}\right)$, residual volume (RV), and forced expiratory flow at $75 \%$ of the vital capacity $\left(\mathrm{FEF}_{75}\right)$. Lung function values that were corrected for sex, age, and height were used. We also measured the alveolar-arterial gradient in $\mathrm{O}_{2}$. Arterial blood sampling was performed with patients at rest in the sitting position.

Institutional review board approval was obtained for this retrospective study (CEPRO 2016-031).

\section{Statistical analysis}

Quantitative data are expressed as mean \pm standard deviation (SD) and qualitative data as frequency and percentage. Comparisons of two means were performed using the Student's $t$ test. Comparisons of three means were performed using one-way ANOVA. ANOVA was completed in case of significance by multiple comparisons tests. Comparisons of frequencies were performed using the chi-squared test. A $p$ value $<0.05$ was considered statistically significant. Statistical analysis was performed using $\mathrm{R}$ software version 3.0.2 (R Foundation for Statistical Computing, Vienna, Austria).

\section{Results}

A total of 155 patients were included. Their characteristics are displayed in Table 1. Their mean age was $44.4 \pm$ 16.7 years and 60 (39\%) were men. Eighty-five (54.8\%) patients had ACVRL1/ALK1 mutations, 56 (36.1\%) had ENG mutations, two (1.3\%) had smad4 mutations, and no mutation was identified in $12(7.7 \%)$ patients. Sixtyseven (43.2\%) patients had PAVMs visible on chest CT. PAVMs were more frequent in patients with ENG mutations than in those with $A C V R L 1 / A L K 1$ mutations (66.1\% vs $30.6 \%, p<0.001)$.

There were no significant associations between the presence of PAVMs on chest CT and TLC, RV, VC, FEV 1 , and $\mathrm{FEF}_{75}$. In contrast, the alveolar-arterial gradient in $\mathrm{O}_{2}$ was larger in patients with PAVMs $(14.9 \pm 13.2 \mathrm{mmHg})$ than in those without PAVMs $(10.4 \pm 8.2 \mathrm{mmHg}, p<0.05)$.

To study the effect of the number of PAVMs on lung function, we divided the patients into three groups: no PAVM visible on chest CT $(n=88,56.8 \%)$, one to three

Table 1 Characteristics of the study population $(n=155)$

\begin{tabular}{|c|c|}
\hline AGE (years) & $44.4 \pm 16.7$ \\
\hline MALE SEX (\%) & $60(38.7 \%)$ \\
\hline \multicolumn{2}{|l|}{ MUTATION } \\
\hline ENG & $56(36.1 \%)$ \\
\hline ACVRL1/ALK1 & $85(54.8 \%)$ \\
\hline Smad 4 & $2(1.3 \%)$ \\
\hline No mutation found & $12(7.7 \%)$ \\
\hline \multicolumn{2}{|l|}{ PAVMs } \\
\hline None & $88(56.8 \%)$ \\
\hline 1-3 PAVMs & 45 (29.0\%) \\
\hline$\geq 4$ PAVMs & $22(14.2 \%)$ \\
\hline TLC (\% predicted) & $99.3 \pm 11.8(n=151)$ \\
\hline RV (\% predicted) & $102.5 \pm 26.0(n=151)$ \\
\hline VC (\% predicted) & $102.1 \pm 13.3(n=155)$ \\
\hline $\mathrm{FEV}_{1}(\%$ predicted $)$ & $101.6 \pm 12.9(n=155)$ \\
\hline $\mathrm{FEV}_{1} \mathrm{NC}(\%)$ & $83.8 \pm 11.8(n=155)$ \\
\hline $\mathrm{FEF}_{75}$ (\% predicted) & $79.8 \pm 29.5(n=154)$ \\
\hline $\mathrm{A}-\mathrm{a} \mathrm{O}_{2}$ gradient $(\mathrm{mmHg})$ & $12.4 \pm 10.9(n=151)$ \\
\hline
\end{tabular}


PAVMs $(n=45,29.0 \%)$, and $\geq$ four PAVMs $(n=22,14.2 \%)$. Age and sex were similar among the three groups. We found no differences in lung function measurements among the groups, except for the alveolar-arterial gradient in $\mathrm{O}_{2}$, which was larger in patients with PAVMs than without $(p<0.01$; Table 2$)$.

To study the effect of size of the PAVMs on lung function, we compared functional data in patients with no PAVMs, those with microscopic PAVMs (defined by a feeding artery with a diameter $<2.5 \mathrm{~mm}$ ), and those with at least one macroscopic PAVM (defined by a feeding artery with a diameter $\geq 2.5 \mathrm{~mm}$ and thus amenable to embolization). Age and sex were similar among the three groups. We found no difference in lung function measurements among the groups, except for the alveolar-arterial gradient in $\mathrm{O}_{2}$, which was larger in patients with macroscopic PAVMs compared with patients without PAVM and with only microscopic PAVMs $(p<0.0001$ for all comparisons; Table 2).

We also compared functional data in patients with no PAVMs, those with unilateral $\operatorname{PAVM}(\mathrm{s})$, and those with bilateral PAVMs. Age and sex were similar among the three groups. We found no difference in lung function measurements among the groups, except for the alveolar-arterial gradient in $\mathrm{O}_{2}$, which was larger in patients with bilateral PAVMs compared with patients without PAVM $(p<0.01)$ and with only unilateral PAVM(s) $(p<0.05)$ (Table 2).

\section{Discussion}

To the best of our knowledge, our study is the largest to evaluate the effect of PAVMs on lung mechanical properties. Our main finding is the absence of an effect of PAVMs, even in patients with numerous and/or bilateral PAVMs. As expected, there was a significant relationship between the alveolar-arterial $\mathrm{O}_{2}$ gradient, and the number and size of PAVMs.

Vascular disease may affect lung mechanics. Previous studies on pulmonary function in patients with pulmonary arterial hypertension (PAH) have reported a restrictive defect [13] or reduced expiratory flow at low lung volumes [14]. This flow limitation may be present in up to $60 \%$ of patients with PAH. Another study showed that, in young nonsmoking patients with $\mathrm{PAH}$, reduced expiratory flow at low lung volumes was associated with dynamic hyperinflation in response to an exerciserelated increase in ventilation [15]. This finding suggests that abnormal ventilatory mechanics may contribute to the genesis of dyspnea in these patients. Therefore, in our series, we did not include patients with PAVMs and signs of PAH on echocardiography. Our results differ from those in patients with PAH.

Dyspnea in patients with PAVMs is considered to mainly result from hypoxemia caused by right-to-left shunting [1]. Other causes of dyspnea in patients with PAVMs may include anemia, $\mathrm{PAH}$, and high-output cardiac failure resulting from diffuse liver vascular

Table 2 Comparison of lung function data between groups of patients according to the number, the size or the uni- or bilateral localization of the PAVMs

\begin{tabular}{|c|c|c|c|c|c|c|}
\hline & TLC (\% pred.) & RV (\% pred.) & VC (\% pred.) & $\mathrm{FEV}_{1}$ (\% pred.) & $\mathrm{FEF}_{25}$ (\% pred.) & $\begin{array}{l}\text { A-a } \mathrm{O}_{2} \text { gradient } \\
(\mathrm{mmHg})\end{array}$ \\
\hline \multicolumn{7}{|l|}{ Number } \\
\hline No PAVM & $98.7 \pm 11.7(n=86)$ & $102.9 \pm 26.1 \quad(n=86)$ & $101.7 \pm 12.4(n=88)$ & $101.4 \pm 12.3(n=88)$ & $80.4 \pm 27.8(n=87)$ & $10.4 \pm 8.2(n=84)$ \\
\hline 1-3 PAVMs & $99.4 \pm 11.9(n=45)$ & $99.0 \pm 24.7(n=45)$ & $103.8 \pm 14.0(n=45)$ & $102.9 \pm 12.1 \quad(n=45)$ & $79.1 \pm 30.4(n=45)$ & $13.3 \pm 12.0(n=45)$ \\
\hline$\geq 4$ PAVMS & $101.9 \pm 11.8(n=20)$ & $108.7 \pm 28.7(n=20)$ & $100.4 \pm 15.5(n=22)$ & $99.7 \pm 16.8(n=22)$ & $78.7 \pm 35.2(n=22)$ & $18.2 \pm 15.3(n=22)$ \\
\hline$p$ & NS & NS & NS & NS & NS & 0.009 \\
\hline \multicolumn{7}{|l|}{ Size } \\
\hline No PAVM & $98.7 \pm 11.7(n=86)$ & $102.9 \pm 26.1(n=86)$ & $101.7 \pm 12.4(n=88)$ & $101.4 \pm 12.3(n=88)$ & $80.4 \pm 27.8(n=87)$ & $10.4 \pm 8.2(n=84)$ \\
\hline $\begin{array}{l}\text { Microscopic } \\
\text { PAVM(s) }\end{array}$ & $100.7 \pm 11.5(n=45)$ & $97.1 \pm 23.7(n=45)$ & $104.5 \pm 13.1(n=47)$ & $103.4 \pm 12.7(n=47)$ & $82.2 \pm 31.2(n=47)$ & $10.9 \pm 9.2(n=47)$ \\
\hline $\begin{array}{l}\geq 1 \text { macroscopic } \\
\text { PAVM }\end{array}$ & $99.0 \pm 12.7(n=20)$ & $113.0 \pm 28.7(n=20)$ & $98.3 \pm 16.8(n=20)$ & $98.0 \pm 15.8(n=20)$ & $71.5 \pm 32.6(n=20)$ & $24.5 \pm 16.3(n=20)$ \\
\hline$p$ & NS & NS & NS & NS & NS & 0.0001 \\
\hline \multicolumn{7}{|l|}{ Uni- or bilateral } \\
\hline No PAVM & $98.7 \pm 11.7(n=86)$ & $102.9 \pm 26.1 \quad(n=86)$ & $101.7 \pm 12.4(n=88)$ & $101.4 \pm 12.3(n=88)$ & $80.4 \pm 27.8(n=87)$ & $10.4 \pm 8.2(n=84)$ \\
\hline Unilateral PAVM(s) & $100.1 \pm 12.2(n=38)$ & $101.8 \pm 25.0(n=38)$ & $102.7 \pm 13.1(n=38)$ & $102.7 \pm 12.3(n=38)$ & $80.4 \pm 29.4(n=38)$ & $11.9 \pm 10.0(n=38)$ \\
\hline Bilateral PAVMs & $100.2 \pm 11.5(n=27)$ & $102.3 \pm 28.3(n=27)$ & $102.6 \pm 16.4(n=29)$ & $100.7 \pm 15.6(n=29)$ & $77.2 \pm 35.1(n=29)$ & $18.9 \pm 15.9(n=29)$ \\
\hline$p$ & NS & NS & NS & NS & NS & 0.001 \\
\hline
\end{tabular}


malformations. Our results suggest that PAVMs do not contribute to dyspnea through alteration of lung mechanics.

This study has several limitations: first, it was a singlecenter, retrospective study. Second, we focused only on resting pulmonary function and did not attempt to measure lung function during exercise. Third, PFTs values are insensitive to small changes in lung mechanics, especially small airways. However, small changes in lung mechanics are unlikely to have a significant clinical impact in these patients. Finally, we did not include a non-HHT control group to determine the impact of HHT itself (without detectable PAVM) on lung mechanics.

\section{Conclusions}

In conclusion, we found no association between the presence of PAVMs in patients with HHT and mechanical properties of the lung as evaluated using routine PFTs, even in patients with numerous, macroscopic or bilateral malformations, suggesting that the presence of PAVMs does not contribute to the patients'dyspnea by a mechanical effect.

\section{Abbreviations \\ ACVRL1/ALK1: Activin A receptor type Il-like 1; ANOVA: Analysis of variance; $\mathrm{CT}$ : Computed tomography; ENG: Endoglin; $\mathrm{FEF}_{75}$ : Forced expiratory flow at $75 \%$ of the vital capacity; $F_{E V}$ : Forced expiratory volume in one second; HHT: Hereditary haemorrhagic telangiectasia; PAH: Pulmonary arterial hypertension; PAVM: Pulmonary arteriovenous malformations; PFTs: Pulmonary function tests; RLS: Right-to-left shunt; RV: Residual volume; SD: Standard deviation; TLC: Total lung capacity; VC: Vital capacity}

\section{Acknowledgements}

The authors acknowledge the members of the multidisciplinary team dedicated to patients with HHT, and especially Isabelle Bourgault-Villada, Philippe Charron, Bénédicte Chesneau, Carole Fagnou, Jérôme Lesniak, Gilles Lesur, and Augustin Ozanne.

\section{Funding}

No funding.

\section{Availability of data and materials}

Please contact author for data request.

\section{Authors' contributions}

TC initiated the study and supervised data collection, data analysis and writing of the manuscript. $T C, M B$ and $A B$ contributed to the study concept and design. TC and CR wrote the first draft of the manuscript, which was critically reviewed by $M B$. AB developed the statistical analysis plan. $C R, M B$, $\mathrm{MEH}, \mathrm{SB}$ and PL participated in data collection and in revision of the manuscript. All authors read, provided input, and gave final approval the version to be published.

\section{Competing interests}

All authors declare that they have no competing interests.

\section{Consent for publication}

Not applicable.

\section{Ethics approval and consent to participate}

Institutional review board approval was obtained for this retrospective study (CEPRO 2016-031). Due to the retrospective nature of this work and the absence of modification of the patients' usual care, the patients' consent to participate was not required. This study was submitted to the Société de
Pneumologie de Langue Française (SPLF) institutional review board (CEPRO) which approved the waiver (CEPRO 2016-031). This study was performed in accordance with the French regulations.

\section{Publisher's Note}

Springer Nature remains neutral with regard to jurisdictional claims in published maps and institutional affiliations.

Received: 26 October 2016 Accepted: 11 April 2017

Published online: 19 April 2017

\section{References}

1. Cartin-Ceba R, Swanson KL, Krowka MJ. Pulmonary arteriovenous malformations. Chest. 2013;144:1033-44.

2. Lacombe P, Lacout A, Marcy PY, Binsse S, Sellier J, Bensalah M, et al. Diagnosis and treatment of pulmonary arteriovenous malformations in hereditary hemorrhagic telangiectasia : an overview. Diagn Interv Imaging. 2013;94: 835-48.

3. Faughnan ME, Palda VA, Garcia-Tsao G, Geisthoff UW, McDonald J, Proctor $\mathrm{DD}$, et al. International guidelines for the diagnosis and management of hereditary haemorrhagic telangiectasia. J Med Genet. 2011;48:73-87.

4. Kjeldsen $A D, O x h o j ~ H$, Andersen PE, Green A, Vase P. Prevalence of pulmonary arteriovenous malformations (PAVM) and occurrence of neurological symptoms in patients with hereditary haemorrhagic telangiectasia (HHT). J Intern Med. 2000;248:255-62

5. Moussouttas M, Fayad P, Rosenblatt M, Hashimoto M, Pollak J, Henderson K, et al. Pulmonary arteriovenous malformations: cerebral ischemia and neurologic manifestations. Neurology. 2000;55:959-64.

6. Pollak JS, Saluja S, Thabet A, Henderson KJ, Denbow N, White RI. Clinical and anatomic outcomes after embolotherapy of pulmonary arteriovenous malformations. J Vasc Interv Radiol. 2006:17:35-44.

7. Cottin V, Chinet T, Lavolé A, Corre R, Marchand E, Reynaud-Gaubert M, et al. Pulmonary arteriovenous malformations in hereditary hemorrhagic telangiectasia: a series of 126 patients. Medicine. 2007:86:1-17.

8. Shovlin CL. Pulmonary arteriovenous malformations. Am J Respir Crit Care Med. 2014;190:1217-28.

9. Terry PB, White RI, Klemens HB, Kaufman SL, Mitchell SE. Pulmonary arteriovenous malformations. Physiologic observations and results of therapeutic balloon embolization. N Engl J Med. 1983;308:1197-200.

10. Pennington DW, Gold WM, Gordon RL, Steiger D, Ring EJ, Golden JA. Treatment of pulmonary arteriovenous malformations by therapeutic embolization. Rest and exercice physiology in eight patients. Am Rev Respir Dis. 1992;145:1047-52.

11. Dutton JAE, Jackson JE, Hughes JMB, Whyte MKB, Peters AM, Ussov W, et al. Pulmonary arteriovenous malformations: results of treatment with coil embolization ni 53 patients. AJR. 1995;165:1119-25.

12. Howard LSGE, Santhirapala V, Murphy K, Mukherjee B, Busbridge M, Tighe $\mathrm{HC}$, et al. Cardiopulmonary exercise testing demonstrates maintenance of exercice capacity in patients with hypoxemia and pulmonary arteriovenoux malforamations. Chest. 2014;146:709-18.

13. Sun XG, Hansen JE, Oudiz RJ, Wasserman K. Pulmonary function in primary pulmonary hypertension. J Am Coll Cardiol. 2003;41:1028-35.

14. Meyer FJ, Ewert R, Hoeper MM, Olschewski H, Behr J, Winkler J, et al. Peripheral airway obstruction in primary pulmonary hypertension. Thorax. 2002;57:473-6.

15. Laveneziana P, Garcia G, Joureau B, Nicolas-Jilwan F, Brahimi T, Laviolette L, et al. Dynamic respiratory mechanics and exertional dyspnoea in pulmonary arterial hypertension. Eur Respir J. 2013;41:578-87. 